\title{
pH-Responsive polypseudorotaxane synthesized through cucurbit|6]uril catalyzed 1,3-dipolar cycloaddition
}

\author{
Dönüs Tuncel, ${ }^{* a}$ H. Burak Tiftik ${ }^{a}$ and Bekir Salih ${ }^{b}$ \\ Received 10th April 2006, Accepted 21st June 2006 \\ First published as an Advance Article on the web 5th July 2006 \\ DOI: $10.1039 / \mathrm{b} 605057 \mathrm{c}$
}

A pH-responsive polypseudorotaxane has been synthesized via cucurbit[6]uril (CB6)-catalyzed 1,3-dipolar cycloaddition using diazide and dialkyne monomers, which contain a long aliphaticspacer. The polypseudorotaxane was characterized by spectroscopic techniques $\left({ }^{1} \mathrm{H},{ }^{13} \mathrm{C}\right.$ NMR and FT-IR) and matrix assisted laser desorption time-of-flight mass spectrometry (MALDI-TOF MS). The experimental results reveal that this polypseudorotaxane behaves as a $\mathrm{pH}$-driven polymeric switch. Thus, when amine groups are protonated at an appropriate $\mathrm{pH}, \mathrm{CB} 6 \mathrm{~s}$ are located on the triazole rings due to ion-dipole interaction, whereas at high $\mathrm{pH}$ they move onto the hydrophobic aliphatic spacer rather than slipping off the polypseudorotaxane.

\section{Introduction}

Increasing demands for materials with defined functions and properties encourage chemists to develop novel methodologies to synthesize them. To this end, mechanically interlocked polymers such as polypseudorotaxanes and polyrotaxanes, which are prepared through non-covalent interactions, are getting increasing attention due to their tunable properties. ${ }^{1}$ For instance by encapsulation of a polymer with a suitable macrocycle, solubility, chemical and thermal stability, and the luminescent efficiency of the polymers can be altered. ${ }^{2 a}$ Furthermore, stimuli-responsive polyrotaxanes can be used as smart materials and in drug-delivery systems. ${ }^{2 b, c}$

Cyclodextrins, crown ethers, and cyclophanes, are the most widely used macrocyles, ${ }^{3}$ but recently cucurbit[6]uril ${ }^{4}$ and its homologues ${ }^{5}$ have joined them as macrocycles in the synthesis of polypseudorotaxanes, and polyrotaxanes. ${ }^{6}$

Cucurbituril is prepared from the acid condensation of glycoluril and formaldehyde and possesses a hydrophobic cavity, along with two matching hydrophilic carbonyl portals. Due to these structural features, CB6 can bind well with protonated mono- and di-aminoalkanes mainly through iondipole interactions and hydrophobic effect. Moreover, CB6 has been shown to catalyze 1,3-dipolar cycloaddition between properly functionalized alkyne and azide groups to yield 1,4disubstituted triazoles. A number of rotaxanes and polyrotaxanes have been designed and synthesized by using the catalytic effect of CB6. ${ }^{7}$

Recently, Steinke and Tuncel reported the synthesis and the polymerisation mechanism of water soluble CB6-based polyrotaxanes prepared through 1,3-dipolar cycloaddition catalyzed by CB6. ${ }^{8}$ In this work, it was found that properly designed monomers are crucial for the formation of polypseudorotaxanes and polyrotaxanes. For example, when dialkyne and diazide functionalized monomers containing an aliphatic spacer such as hexamethylene were used, the

${ }^{a}$ Chemistry Department, Bilkent University, 06800 Ankara, Turkey.

E-mail:dtuncel@fen.bilkent.edu.tr

${ }^{b}$ Chemistry Department, Hacettepe University, 06580 Ankara, Turkey corresponding polypseudorotaxane failed to form. This was mainly attributed to the slow dissociation rate constant in conjunction with the large complexation constant between the CB6 and the 1,6-hexamethylene diammonium part of the dialkyne and diazide monomers. Thus, only a minute amount of CB6 was available to form a ternary complex between the alkyne and azide species, and CB6. However, this step is critical in allowing CB6 to catalyze 1,3-dipolar cycloadditions which in turn leads to triazole ring formation.

Herein, we wish to revisit the catalytic self-threading synthesis of polypseudorotaxanes by modifying the structures of monomers used in the previous study and prove that the choice of spacers in the monomer design is indeed crucial. The new monomers contain a long aliphatic spacer, namely dodecamethylene, which has lower binding affinity toward CB6 than the azidoethylammonium and propargylammonium part of the monomers. ${ }^{9}$ After the synthesis of the desired polyseudorotaxane, we wish also to investigate the $\mathrm{pH}$ dependent movement of CB6 over the polymer chain.

\section{Result and discussion}

\section{Synthesis and characterization of monomers and polypseudorotaxane}

Monomers dialkyne $\mathbf{2}$ and diazide $\mathbf{3}$ and polypseudorotaxanes 4 were prepared as shown in Scheme 1. The monomer 2 was synthesized by the reaction of dibromododecane with excess propargylamine in chloroform followed by the protonation of the dipropargylic amine species using $0.1 \mathrm{M} \mathrm{HCl}$ solution in diethylether. The resulting hydrochloride salt was purified by recystallization from water to produce 2 in $75 \%$ yield.

To synthesize monomer $\mathbf{3}$, first chloroethylamine hydrochloride was converted to azidoethylamine by a nucleophilic substitution reaction with sodium azide in water. Then, 1,12dibromododecane was $N$-alkylated by treatment with excess azidoethylamine followed by the conversion of the diazidoamine species to its hydrochloride salt $\mathbf{3}$. The monomer $\mathbf{3}$ was obtained in $80 \%$ yield after recystallization from ethanol. 


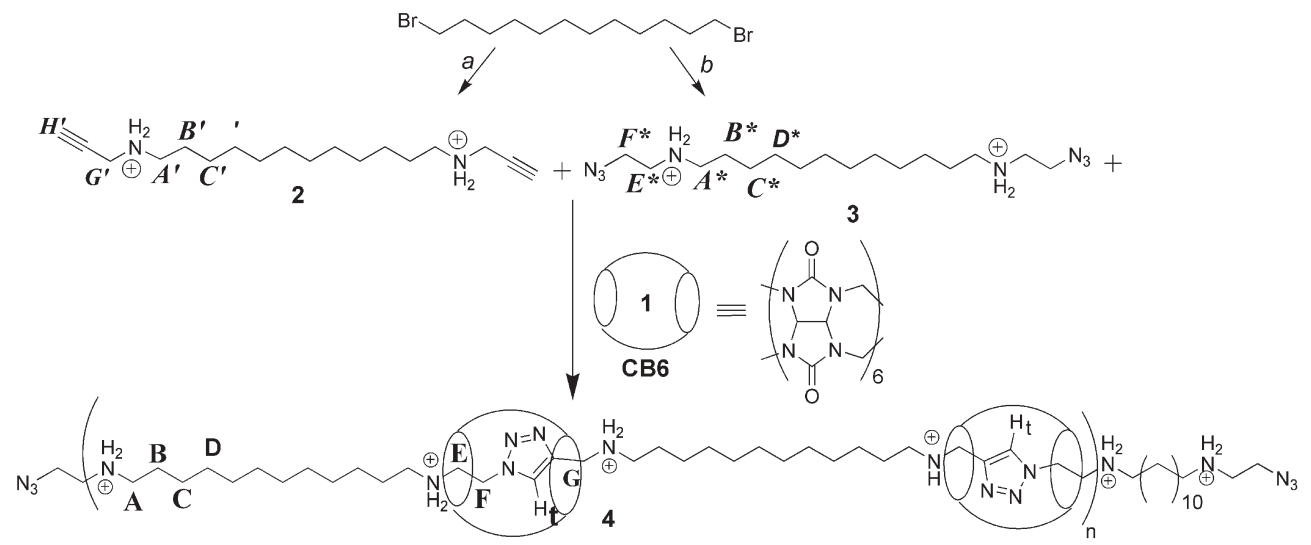

Scheme 1 (a) Excess propargylamine, in $\mathrm{CHCl}_{3}, 25^{\circ} \mathrm{C}, 72 \mathrm{~h} ; 0.1 \mathrm{M} \mathrm{HCl}$ in diethylether, $24 \mathrm{~h}, 25{ }^{\circ} \mathrm{C}, 75 \%$. (b) $\mathrm{Excess}_{2} \mathrm{H}_{2} \mathrm{NCH}_{2} \mathrm{CH}_{2} \mathrm{~N}_{3}$, in $\mathrm{CH}_{2} \mathrm{Cl}_{2}$, $25^{\circ} \mathrm{C}, 72 \mathrm{~h} ; 0.1 \mathrm{M} \mathrm{HCl}$ in diethylether, $25^{\circ} \mathrm{C}, 24 \mathrm{~h}, 80 \%$. Pseudopolyrotaxane 4 formation: 1 equiv. 2,1 equiv. 3 and 2 equiv. $1,6 \mathrm{M} \mathrm{HCl}, 60{ }^{\circ} \mathrm{C}$, $48 \mathrm{~h}, 80 \%$. (Counter-ions chloride were omitted for clarity).

The monomers $\mathbf{2}$ and $\mathbf{3}$ were characterized by spectroscopic methods $\left({ }^{1} \mathrm{H}\right.$ and ${ }^{13} \mathrm{C}$ NMR, FT-IR), as well as elemental analysis. The results are in good agreement with the proposed structures.

To synthesize the polypseudorotaxane 4 , one equiv. of monomer $\mathbf{2}$ and one equiv. of monomer $\mathbf{3}$ were dissolved in water at $60{ }^{\circ} \mathrm{C}$ followed by the addition of two equiv. of CB6 in $6 \mathrm{M} \mathrm{HCl}$. The resulting solution was stirred at $60{ }^{\circ} \mathrm{C}$ and after $48 \mathrm{~h}$ the solvent was removed under reduced pressure. The resulting light yellow film was redissolved in water and purified by dialysis using a membrane with a nominal molecular weight cut-off of $5 \mathrm{kDa}$. Polypseudorotaxane was obtained in $80 \%$ yield as a colourless film after the removal of solvent and drying the film under vacuum at $40{ }^{\circ} \mathrm{C}$ for $12 \mathrm{hr}$.

The formation of polypseudorotaxane $\mathbf{4}$ was confirmed first by ${ }^{1} \mathrm{H}$ NMR spectroscopy. Fig. 1 compares the ${ }^{1} \mathrm{H}$ NMR spectra of the monomers $\mathbf{2}$ and $\mathbf{3}$, and the polypseudorotaxane $\mathbf{4}$.

Upon the formation of $\mathbf{4}$, a new resonance at $6.5 \mathrm{ppm}$ appears which is a diagnostic signal for the proton of a threaded triazole ring (Fig. 1c). In addition, the signal of the terminal proton of alkyne proton at $2.9 \mathrm{ppm}$ is not observed in the ${ }^{1} \mathrm{H}$ NMR spectrum of 4 ; this further indicates the formation of a triazole ring.

One can also determine the location of CB6 from the ${ }^{1} \mathrm{H}-\mathrm{NMR}$ spectrum of $\mathbf{4}$. If the dodecamethylene spacer was threaded by $\mathrm{CB} 6$, the resonances due to its protons would shift

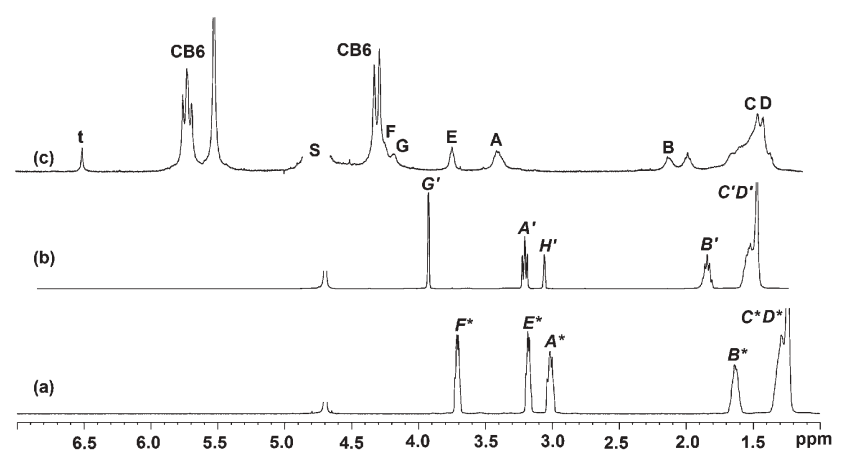

Fig. $1{ }^{1} \mathrm{H}$ NMR $\left(400 \mathrm{MHz}, \mathrm{D}_{2} \mathrm{O}, 25^{\circ} \mathrm{C}\right)$ spectra of (a) monomer 3, (b) monomer 2, (c) polypseudorotaxane 4 (S: solvent, HOD). significantly to upfield because of the shielding effect of CB6. However, the spectrum clearly shows that CB6 is localized on the triazole ring, but not on the dodecamethylene spacer.

The number-average molecular weight of the polypseudorotaxane can be estimated by comparing the integral intensities of the threaded triazole proton $(t)$ to the central methylene protons of dodecamethylene spacer $(C$ and $D)$ at 6.5 and $1.5 \mathrm{ppm}$ respectively (Scheme 1). Each repeat unit, which has the molecular weight of approximately $2600 \mathrm{Da}$, contains two triazole protons $(t)$ and a total of 32 central methylene protons $(C$ and $D$ ). The ratio of $t$ to $C+D$ should be $1: 16$ for an infinite polymer chain. From the integration, the ratio was calculated as $1: 17(t / C+D)$ which corresponds to repeat unit of eight. Thus, the number-average molecular weight of the polymer corresponds to about $20800 \mathrm{Da}$.

In the IR spectrum of $\mathbf{4}$, a very weak signal due to azide stretching at $2200 \mathrm{~cm}^{-1}$ was observed, which probably belongs to an azide end group rather than to the unreacted monomer. Having very weak signal for the azide stretching also indicates the formation of a polypseudorotaxane, because when we mix mechanically one equivalent of dialkyne and one equivalent of diazide monomers, and two equivalents of CB6 and then record the IR spectrum of this mixture, we observe the azide stretching peak with a very strong intensity.

It is known that the molecular weight determination of polyelectrolytes like ours is quite troublesome. So we were not able to determine the molecular weight of the polypseudorotaxane with techniques other than the matrix assisted laser desorption time-of-flight mass spectrometry (MALDI-TOF MS).

MALDI-TOF MS verifies the formation of 4 (Fig. 2). The positive ion MALDI-MS spectrum of polypseudorotaxane was recorded using 3-indoleacrylic acid as a matrix. Peak groups were observed repeating by approximately $2600 \mathrm{Da}$ mass unit intervals. Beside the potassium adducts of dimer, tetramer, hexamer, octamer, decamer and dodecamer other unidentified peaks were detected. Maximum mass was observed around $15600 \mathrm{Da}$ which corresponds to about six repeating units, that is basically $12 \mathrm{CB} 6 \mathrm{~s}$ threaded triazoles.

In the MALDI MS spectrum, we would not expect to observe the molecular ions lower than 5000 Da because the polymer was purified by dialysis using a membrane with a 


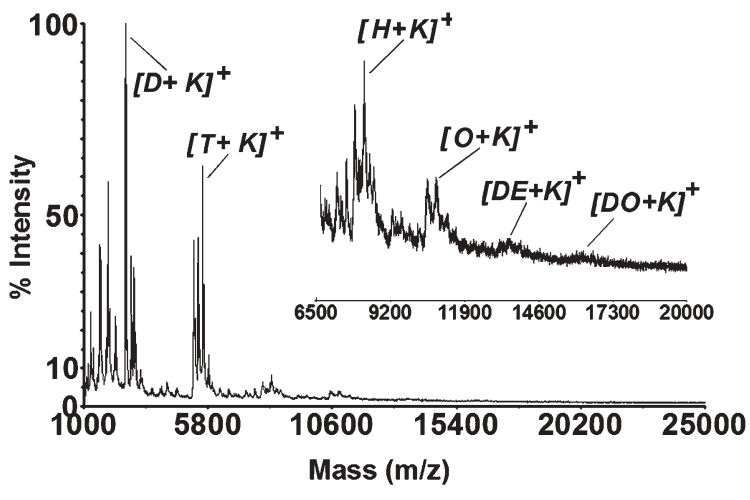

Fig. 2 Positive ion MALDI-MS spectrum of polypseudorotaxane 4 in indole acrylic acid matrix. Inset shows expanded region between 6500 and 20000 Da mass ranges (Potassium (K) adducts of D: dimer, T: detramer, H: hexamer, O: octamer, DE: decamer, DO: dodecamer).

nominal molecular weight cut-off of $5 \mathrm{kDa}$ for a prolonged time. Nevertheless, low molecular weight ions with high intensity in MS spectrum were detected. One can speculate that the dialysis may cause the dethreading of CB6 macrocycles from the polymer and consequently leave behind a low molecular weight polymer. This possibility can be ruled out because the ${ }^{1} \mathrm{H}-\mathrm{NMR}$ spectrum of the dialysed polypseudorotaxane does not reveal the presence of chemical shifts due to unencapsulated triazole protons. Moreover, the ratio of threaded triazole proton to central methylene protons of dodecyl spacer even increased after the dialysis.

Thus, having intense peaks for low molecular weight ions can be attributed to the fact that MALDI MS does not provide quantitative information on the molecular weight distribution for polyelectrolytes because the polymer chains with low molecular weight are transferred to gas phase more easily. Low mass signals might arise from fragmentation of the polypseudorotaxane under laser energy or due to dethreading CB6s from 4 because unidentified signals were detected in the spectrum. Another explanation for the low mass signals can be the presence of multi-charged species. However, we do not have direct evidences for these possibilities.

\section{Investigation of $\mathrm{pH}$-driven switching properties of polypseudorotaxane 4}

Next, we attempted to dethread CB6 from polypseudorotaxane 4 to obtain the polytriazole. In order to do this, the ion-dipole interactions between the diammonium ions and carbonyl groups of CB6 must first be disrupted by deprotonation of the ammonium ions with a base.

To perform the dethreading experiment, $\mathbf{4}$ was dissolved in water and $0.1 \mathrm{M}$ aqueous solution of $\mathrm{NaOH}$ was added to this solution. Instantly a white gel formed; it was isolated by centrifugation and washed with water several times and then with $0.2 \mathrm{M}$ aqueous solution of $\mathrm{NaCl}$ to remove $\mathrm{CB}$, in case any was left. The wash solution was evaporated to dryness and the IR spectrum of the residue was recorded, however, no CB6 was detected.

The isolated solid was found to be insoluble in any common organic solvent. However, when it was treated with $0.1 \mathrm{M} \mathrm{HCl}$ solution, it became soluble. Interestingly, it was found that the ${ }^{1} \mathrm{H}-\mathrm{NMR}$ spectrum of this solid (in $\mathrm{D}_{2} \mathrm{O}-\mathrm{HCl}$ ) and its IR spectrum are similar to the spectrum of polypseudorotaxane 4 .

This result suggests that once the ion-dipole interaction between the ammonium ions and the carbonyl groups of CB6 is disrupted at an appropriate $\mathrm{pH}, \mathrm{CB} 6$ shuttles to the more hydrophobic part, the dodecamethylene spacer, rather than dethreading from the polypseudorotaxane. Upon protonation of the nitrogens, it moves back on the triazole ring, where via ion-dipole interaction it forms stronger complexes with each of the two positively charged nitrogen atoms on the amines (Scheme 2).

To reveal the details of the $\mathrm{pH}$-driven movement of $\mathrm{CB} 6$ in 4, we followed the acid-base switching by ${ }^{1} \mathrm{H}$ NMR spectroscopy; the spectra of $\mathbf{4}$ in $\mathrm{D}_{2} \mathrm{O}$ were recorded at varying $\mathrm{pHs}$ using $\mathrm{NaOH}$ and $\mathrm{HCl}$ (Fig. 3). They were recorded in each case about five minutes later addition of base or acid to the solution of polypseudorotaxane.

Up to $\mathrm{pH} 9$, no significant spectral changes were observed. As shown in Fig. 3b, at $\mathrm{pH} 9$, the intensity of the resonance due to the encapsulated triazole proton at $6.5 \mathrm{ppm}$ decreases, whereas three weak signals around at $8 \mathrm{ppm}$ due to unencapsulated triazole ring proton emerge. The appearance of three different signals due to unencapsulated triazole proton indicates that they are in different chemical environments. Furthermore, a new signal at $2.5 \mathrm{ppm}$ appears; this signal can be assigned to protons $\mathrm{b}$ by assuming that they are adjacent to the carbonyl groups of CB6 and as a result, shifted downfield. All these spectral changes can be ascribed to the partial movement of CB6 rings from the triazole site to the dodecamethylene spacer that driven by the partial deprotonation of ammonium ions at $\mathrm{pH} 9$.

The CB6 rings are probably quite mobile and moving back and forth over the long dodecamethylene spacer. As a result, averaged signals due to the protons of central methylene

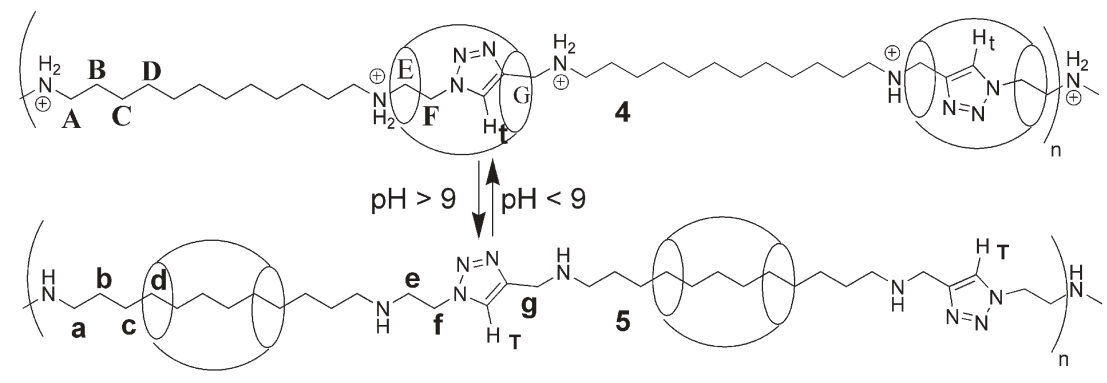

Scheme 2 


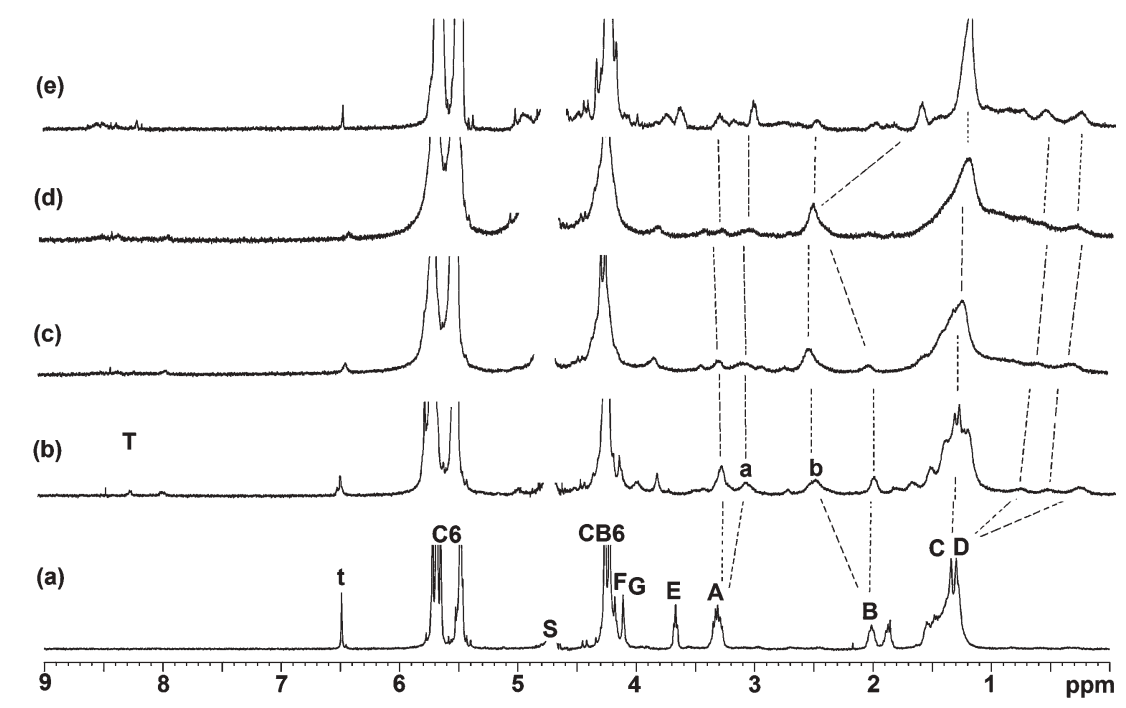

Fig. $3{ }^{1} \mathrm{H}$ NMR $\left(400 \mathrm{MHz}, \mathrm{D}_{2} \mathrm{O}, 25^{\circ} \mathrm{C}\right)$ spectra of 4 at varying pHs, (a) $\mathrm{pH}$ 5, (b) $\mathrm{pH}$ 9, (c) $\mathrm{pH} 10$, (d) $\mathrm{pH} 11$ (e) $\mathrm{After}$ addition of $\mathrm{HCl}$, pH $\sim 5$ (S: solvent, HOD).

groups of dodecamethylene spacer are observed in the ${ }^{1} \mathrm{H}-\mathrm{NMR}$ spectrum. At $\mathrm{pH}$ 9, from the integration of resonances due to threaded triazole proton and CB6 protons, it is estimated that approximately $50 \%$ of CB6s are located on the triazole part and the rest on the dodecamethylene spacer, whereas at pH 10 (Fig. 3c), approximately 20\% of CB6 reside on the triazole part and the rest on the dodecamethylene part. At $\mathrm{pH} 11$, the ${ }^{1} \mathrm{H}$ NMR spectrum reveals that almost $95 \%$ of $\mathrm{CB} 6 \mathrm{~s}$ reside on the dodecamethylene spacer. Increasing the $\mathrm{pH}$ of the solution beyond 11 causes immediate precipitation.

However, the addition of $\mathrm{HCl}$ causes the dissolution of the precipitate in a few minutes. ${ }^{1} \mathrm{H}-\mathrm{NMR}$ spectrum is recorded about five minutes later the addition of $\mathrm{HCl}(\mathrm{pH} \sim 5)$ to the precipitate. The spectrum reveals that most of the CB6s shuttle back to their initial location, which is the triazole site. The signal due to encapsulated proton at $6.5 \mathrm{ppm}$ reappears and the signal at $2.5 \mathrm{ppm}$ almost disappears.

\section{Conclusions}

In this paper, we reported the synthesis and characterization of a novel $\mathrm{pH}$-responsive CB6-based polypseudorotaxane prepared via 1,3-dipolar cycloaddition catalyzed by CB6. The result confirms the critical role of spacers employed in the monomers for catalytic self-threading synthesis of polypseudorotaxanes.

The experimental results reveal that the polypseudorotaxane behaves as a $\mathrm{pH}$-driven polymeric switch. Thus, once the iondipole interaction between the ammonium ions and the carbonyl groups of $\mathrm{CB} 6$ is disrupted at an appropriate $\mathrm{pH}$, CB6 shuttles to the hydrophobic part of the polymer, the dodecamethylene spacer, rather than de-threading from the polypseudorotaxane. Hence, it forms a relatively stable complex with the dodecamethylene spacer via hydrophobic interaction. However, upon protonation of the amine groups, it moves back on the triazole ring, where via ion-dipole interaction it forms stronger complexes with each of the two positively charged nitrogen atoms on the amines.
A detailed investigation of the properties of this novel polypseudorotaxane and the synthesis of its polytriazole by de-threading, and using other approaches are currently in progress.

\section{Experimental}

CB6 was prepared according to literature. ${ }^{8}$ All other reagents and solvents were of the commercial reagent grade and used without further purification except where noted. Nuclear magnetic resonance (NMR) spectra were recorded on a Bruker Avance DPX-400 MHz spectrometer. In all cases, samples were dissolved in $\mathrm{D}_{2} \mathrm{O}$ with DSS (3-(trimethylsilyl)-1propanesulfonic acid sodium salt) as an external standard.

Mass spectra were acquired on a Voyager-DETM PRO MALDI-TOF mass spectrometer (Applied Biosystems, USA) equipped with a nitrogen UV-Laser $(\lambda=337 \mathrm{~nm})$ at $10-7$ Torr and delayed extraction mode (delay $300 \mathrm{~ns}$ ) by changing the laser intensity, if necessary. All spectra were acquired in reflector mode using $20 \mathrm{kV}$ acceleration potential and they were the average of 200 laser shots. Then, data were transferred to a personal computer for further processing. 3-Indoleacrylic acid (IAA) (Fluka, Switzerland) was chosen as the best MALDI matrix and prepared in $\mathrm{MeOH}$ at a concentration of $20 \mathrm{mg} \mathrm{mL}^{-1}$. MALDI samples were prepared by mixing the sample solution with the IAA matrix solution $(1: 10 \mathrm{v} / \mathrm{v})$ in a $0.5 \mathrm{~mL}$ Eppendorf $\AA$ micro tube. Finally $0.1 \mu \mathrm{L}$ of these mixtures were deposited on the sample plate, dried in room temperature and then analyzed.

Dialysis was carried out in an Amicon8200 ultrafiltration stirred cell $(200 \mathrm{~mL})$ and polysulfone membranes (NMWCO $5 \mathrm{kDa}$ ). Approximately $2 \mathrm{~L}$ water was eluted through the ultrafiltration cell under 4.5 bar nitrogen pressure.

\section{Synthesis of $N, N^{\prime}$-di-prop-2-ynyldodecane-1,12-diamine dihydrochloride 2}

A solution of 1,12-dibromododecane $(0.93 \mathrm{~g}, 2.8 \mathrm{mmol})$ in $\mathrm{CHCl}_{3}(5 \mathrm{~mL})$ was added dropwise to excess propargylamine 
$(1.56 \mathrm{~g}, 28.4 \mathrm{mmol})$ at room temperature. The resulting solution was stirred at room temperature for 48 h. $0.1 \mathrm{M}$ Aqueous $\mathrm{NaOH}(5 \mathrm{~mL})$ was added to reaction mixture and the mixture was stirred for $1 \mathrm{~h}$ at room temperature. The organic layer was separated by extraction and washed with saturated solution of $\mathrm{NaCl}$. After drying the organic layer over $\mathrm{CaCl}_{2}$, the solvent was removed under reduced pressure. A light yellow solid residue was obtained. It was dissolved in diethylether $(5 \mathrm{~mL})$ and the solution was cooled to $0{ }^{\circ} \mathrm{C}$ in an ice-bath. $0.1 \mathrm{M} \mathrm{HCl}$ in diethyl ether $(5 \mathrm{ml})$ was added dropwise. The resulting mixture was stirred at room temperature for $4 \mathrm{~h}$. A beige precipitate was collected and recrystallized from water to obtain off-white solid.

Yield: 0.75 g, (75\%). M.p.: $218-219^{\circ} \mathrm{C}$

Elemental Analysis for $\mathrm{C}_{18} \mathrm{H}_{34} \mathrm{Cl}_{2} \mathrm{~N}_{2}$

Calc.: C, 61.88; H, 9.81; Cl, 20.29; N, 8.02; Found: C, 61.69; H, 9.35; N, 7.90

IR ( $\mathrm{KBr}$ disk, $\mathrm{cm}^{-1}$ ): $3480(\mathrm{w}), 3385$ (m), 3135 (m), 2452 (m), $2200(\mathrm{w})$.

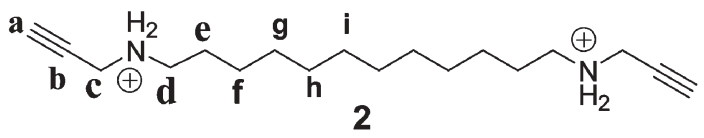

${ }^{1} \mathrm{H}$ NMR (400 MHz, D $\left.2 \mathrm{O}\right): \delta 1.3(\mathrm{~m}, 16 \mathrm{H}, \mathbf{e}, \mathbf{f}), 1.6(\mathrm{~m}, 4 \mathrm{H}, \mathbf{d})$, $2.9\left(\mathrm{t}, 2 \mathrm{H},{ }^{4} J_{\mathrm{HH}} 2.2 \mathrm{~Hz}, \mathrm{~b}\right), 3.1\left(\mathrm{t}, 4 \mathrm{H},{ }^{3} J_{\mathrm{HH}} 7.8 \mathrm{~Hz}, \mathbf{c}\right), \delta 3.9(\mathrm{~d}$, $\left.4 \mathrm{H},{ }^{4} J_{\mathrm{HH}} 2.2 \mathrm{~Hz}, \mathbf{a}\right)$.

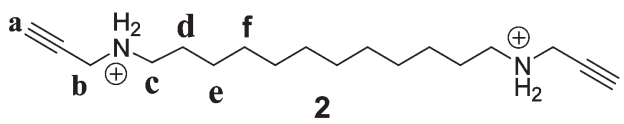

${ }^{13} \mathrm{C}$ NMR (100 MHz, D 2 ): $\delta 25.3$ (i), 25.6 (h), 28.2 (g), 28.4 (f), 28.6 (e), 36.2 (c), 46.8 (d), 73.2 (b), 77.9 (a).

\section{Synthesis of $N, N^{\prime}$-bis(2-azido-ethyl)dodecane-1,12-diamine dihydrochoride 3}

A solution of 1,12-dibromododecane $(0.86 \mathrm{~g}, 2.6 \mathrm{mmol})$ in $\mathrm{CHCl}_{3}(5 \mathrm{~mL})$ was added dropwise to freshly prepared azidoethylamine $^{8}(2.25 \mathrm{~g}, 26.2 \mathrm{mmol})$ at room temperature. The resulting solution was stirred at room temperature for 48 h. $1 \mathrm{M}$ aqueous $\mathrm{NaOH}(5 \mathrm{~mL})$ was added to reaction mixture and the mixture was stirred for $1 \mathrm{~h}$ at room temperature. The organic layer was separated by extraction and washed with saturated $\mathrm{NaCl}$. After drying the organic layer over $\mathrm{CaCl}_{2}$, the solvent was removed under reduced pressure. A light yellow solid residue was obtained. It was dissolved in diethylether $(5 \mathrm{~mL})$ and the solution was cooled to $0{ }^{\circ} \mathrm{C}$ in an ice-bath. $0.1 \mathrm{M} \mathrm{HCl}$ solution in diethylether $(5 \mathrm{~mL})$ was added dropwise. The resulting mixture was stirred at room temperature for $4 \mathrm{~h}$. The solvent was removed under reduced pressure and off-white solid residue was recystallized from ethanol.

Yield: 0.89 g, (80\%). M.p.: > $208{ }^{\circ} \mathrm{C}$ (decomposed)
Elemental Analysis for $\mathrm{C}_{16} \mathrm{H}_{36} \mathrm{Cl}_{2} \mathrm{~N}_{8}$

Calc.: C, 46.71; H, 8.82; N, 27.24; Found: C, 46.75; H, 9.05; N, 26.99

IR ( $\mathrm{KBr}$, pellet, $\mathrm{cm}^{-1}$ ): $3480(\mathrm{w}), 3385$ (m), 3135 (m), 2452 (m), 2131 (vs).

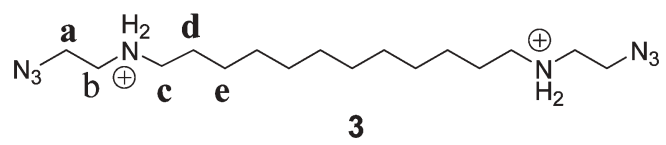

${ }^{1} \mathrm{H}$ NMR (400 MHz, D $\left.2 \mathrm{O}\right): \delta 1.24(\mathrm{~m}, 16 \mathrm{H}, \mathrm{e}), 1.64$ (m, 4H, d), $3.02\left(\mathrm{t}, 4 \mathrm{H},{ }^{3} J_{\mathrm{HH}} 7.1 \mathrm{~Hz}, \mathrm{c}\right), 3.18\left(\mathrm{t}, 4 \mathrm{H},{ }^{3} J_{\mathrm{HH}} 5.4 \mathrm{~Hz}, \mathrm{a}\right), 3.75$ (t, $\left.4 \mathrm{H},{ }^{3} J_{\mathrm{HH}} 5.4 \mathrm{~Hz}, \mathrm{~b}\right)$.

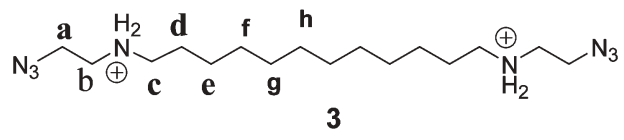

${ }^{13} \mathrm{C}$ NMR (100 MHz, D $2 \mathrm{O}$ ): $\delta 25.4$ (h), 25.7 (g), 28.1 (f), 28.5 (e), 28.7 (d), 46.1 (c), 46.9 (b), 47.8 (a).

\section{Synthesis of polypseudorotaxane 4}

CB6 (400 mg, $0.400 \mathrm{mmol})$ was dissolved in $6 \mathrm{M} \mathrm{HCl}(5 \mathrm{~mL})$ and the resulting solution was stirred for $30 \mathrm{~min}$. Alkyne 2 (69.88 $\mathrm{mg}, 0.200 \mathrm{mmol})$ and subsequently azide $3(85.26 \mathrm{mg}$, $0.200 \mathrm{mmol}$ ) were added under vigorous stirring at room temperature. The resulting solution was stirred at $60{ }^{\circ} \mathrm{C}$ for $48 \mathrm{~h}$. The solvent was removed under reduced pressure to obtain a colorless film, which was redissolved in water and purified by ultrafiltration using a membrane (polyethersulfone) with a nominal weight cut-off of $5 \mathrm{kDa}$. Removal of solvent gave $\mathbf{4}$ as a colorless glassy film.

Yield: $440 \mathrm{mg},(80 \%)$.

Elemental Analysis for $\mathrm{C}_{176} \mathrm{H}_{248} \mathrm{Cl}_{8} \mathrm{~N}_{92} \mathrm{O}_{36} .25 \mathrm{H}_{2} \mathrm{O}$

Calc.: C, 42.58; H, 6.06; N, 25.97; Found: C, 42.84; H, 6.23; N, 25.98

IR (KBr, pellet, $\mathrm{cm}^{-1}$ ): $3443(\mathrm{~m}), 2927(\mathrm{w}), 2353(\mathrm{vw}), 1735$ (vs), 1473 (vs). ${ }^{1} \mathrm{H}$ NMR (400 MHz, D $\left.2 \mathrm{O}\right): \delta 1.2-13(\mathrm{~m}, 16 \mathrm{H}, \mathrm{C}$ + D), 1.8-2.0 (m, 4H, B), 3.2 (m, 4H, A), 3.6 (m, 2H, E), 4.11 $(\mathrm{m}, 2 \mathrm{H}, \mathrm{F}), 4.15(\mathrm{~F}+\mathrm{G}, 3 \mathrm{H}$, overlapped with CB6), $4.16(\mathrm{~d}$, $\left.12 \mathrm{H},{ }^{2} J_{\mathrm{HH}}=15.6 \mathrm{~Hz}, \mathrm{CB} 6\right), 5.45(\mathrm{~s}, 12 \mathrm{H}, \mathrm{CB} 6), 5.94(\mathrm{dd}, 12 \mathrm{H}$, $\left.{ }^{2} J_{\mathrm{HH}}=15.6 \mathrm{~Hz}, \mathrm{CB} 6\right), 6.52(\mathrm{~s}, 1 \mathrm{H}, \mathrm{t})$.

${ }^{13} \mathrm{C}$ NMR (100 MHz, D2O): $\delta$ 25.7, 26.1, 28.3, 28.4, 28.5, 28.7, 42.0, 45.4, 46.1, 48.3, 49.1, 51.3 (CB6), 51.5 (CB6), 70.2 $(\mathrm{CB} 6), 120.1$ (triazole, $=\mathrm{CH}), 139.0($ triazole, $=\mathrm{CR}), 156.2$ (CB6), 156.6 (CB6).

\section{Acknowledgements}

This research was supported by the Scientific and Technical Research Council of Turkey (TUBITAK, Grant No: MISAG 260).

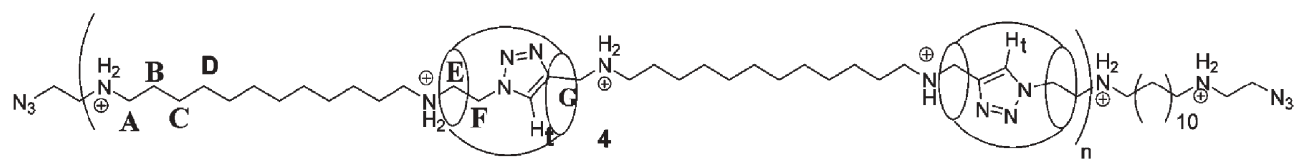




\section{References}

1 (a) Molecular Catenanes, Rotaxanes, and Knots, ed. J.-P.Sauvage, C.O. Dietrich-Buchecker, Wiley-VCH, Weinheim, 1999; (b) F. Huang and H. W. Gibson, Prog. Polym. Sci., 2005, 30, 983.

2 (a) F. Cacialli, J. S. Wilson, J. J. Michels, C. Daniel, C. Silva, R. H. Friend, N. Severin, P. Samori, J. P. Rabe, M. J. O'Connell, P. N. Taylor and H. L. Anderson, Nat. Mater., 2002, 1, 160; (b) J. Watanabe, T. Ooya, K. D. Park, Y. H. Kim and N. Yui, J. Biomater. Sci., Polym. Ed., 2000, 11, 1333; (c) H. S. Choi, K. M. Huh, T. Ooya and N. Yui, J. Am. Chem. Soc., 2003, 125, 6350.

3 (a) S. A. Nepogodiev and J. F. Stoddart, Chem. Rev., 1998, 98, 1959; (b) H. W. Gibson, M. Bheda, P. T. Engen, Y. X. Shen, J. Sze, C. Wu, S. Joardar, T. C. Ward and P. R. Lecavalier, Makromol. Chem., Macromol. Symp., 1991, 42-3, 395; (c) H. W. Gibson, S. H. Lee, P. T. Engen, P. Lecavalier, J. Sze, Y. X. Shen and M. Bheda, J. Org. Chem., 1993, 58, 3748; (d) H. W. Gibson, P. T. Engen and S. H. Lee, Polymer, 1999, 40, 1823; (e) S. H. Lee, P. T. Engen and H. W. Gibson, Macromolecules, 1997, 30, 337; $(f)$ P. N. Taylor, M. J. O'Connell, L. A. McNeill, M. J. Hall, R. T. Aplin and H. L. Anderson, Angew. Chem., Int. Ed., 2000, 39, 3456; $(g)$ A. Harada, J. Li and M. Kamachi, Nature, 1993, 364, 516.
4 (a) W. L. Mock, in Comprehensive Supramolecular Chemistry, ed. F. Vogtle, Pergamon, Oxford, 1996, vol. 2, 477; (b) K. Kim, Chem. Soc. Rev., 2002, 31, 96.

5 J. Kim, I.-S. Jung, S.-Y. Kim, E. Lee, J.-K. Kang, S. Sakamoto, K. Yamaguchi and K. Kim, J. Am. Chem. Soc., 2000, 122, 540.

6 (a) S. Choi, J. W. Lee, Y. H. Ko and K. Kim, Macromolecules, 2002, 35, 3526; (b) Y. Tan, S. Choi, J. W. Lee, Y. H. Ko and K. Kim, Macromolecules, 2002, 35, 7161; (c) C. Meschke, H.-J. Bushmann and E. Schollmeyer, Polymer, 1999, 40, 945; (d) W. Ong, M. GomezKaifer and A. Kaifer, Org. Lett., 2002, 4, 1791; (e) C. Marquez, R. R. Hudgins and W. M. Nau, J. Am. Chem. Soc., 2004, 126, 5806; (f) J. W. Lee, K. Kim and K. Kim, Chem. Commun., 2001, 1042; (g) S. I. Jun, J. W. Lee, S. Sakamoto, K. Yamaguchi and K. Kim, Tetrahedron Lett., 2000, 41, 471; (h) Y. H. Ko, K. Kim, J-K. Kang, H. Chun, J. W. Lee, S. Sakamoto, K. Yamaguchi, J. Fettinger and K. Kim, J. Am. Chem. Soc., 2004, 126, 1932.

7 (a) W. L. Mock, Top. Curr. Chem., 1995, 175, 1; (b) D. Tuncel and J. H. G. Steinke, Chem. Commun., 1999, 1509; (c) D. Tuncel and J. H. G. Steinke, Chem. Commun., 2001, 253; (d) D. Tuncel and J. H. G. Steinke, Chem. Commun., 2002, 496.

8 D. Tuncel and J. H. G. Steinke, Macromolecules, 2004, 37, 288.

9 (a) W. L. Mock and N.-Y. Shih, J. Org. Chem., 1986, 51, 4440; (b) W. L. Mock and N.-Y. Shih, J. Am. Chem. Soc., 1988, 110, 4706.

An exciting news supplement providing a

snapshot of the latest developments across the

chemical sciences

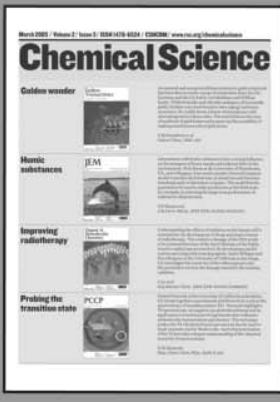

Free online and in print issues of selected RSC journals!*

Research Highlights - newsworthy articles and significant scientific advances

Essential Elements - latest developments from RSC publications

Free access to the originals research paper from every online article

${ }^{*}$ A separately issued print subscription is also available 